\title{
Kind of Black: The Musicians' Labour Market in Italy
}

\author{
Alessandro Balestrino
}

CESIFO WORKING PAPER NO. 2769

CATEGORY 4: LABOUR MARKETS

August 2009

\footnotetext{
An electronic version of the paper may be downloaded

- from the SSRN website:

- from the RePEc website: www.SSRN.com

Www.RePEc.org

- from the CESifo website:

www.CESifo-group.org/wp
} 


\title{
Kind of Black: The Musicians' Labour Market in Italy
}

\begin{abstract}
It is estimated that only 5\% of musicians in Italy are regularly employed. In an attempt at understanding such a peculiar situation, we build a theoretical model of the musicians' labour market in which we embed the main institutional features of the Italian system. We notice how the presence of taxation incentivates the formation of a black market for musicians and discourages talented agents from becoming full-time musicians in all second-best economies. In Italy both tendencies are particularly strong, and further exacerbated by the presence of an actuarially unfair pension system for musicians. These inefficiencies might be corrected by a two-fold policy: the reform of the pension system, and the introduction of a sufficiently large unemployment benefit for musicians. We notice that the first step, while highly desirable, is unlikely to be politically feasible in the current Italian institutional setting. The second step, which has a general interest for any second-best economy, is instead viable under certain circumstances.
\end{abstract}

JEL Code: J44, Z11.

Keywords: musician, labour market, moonlighting, unemployment benefit, Italy.

\author{
Alessandro Balestrino \\ Department of Economics \\ University of Pisa \\ Italy - Pisa \\ balestrino@sp.unipi.it
}

August 12, 2009

I thank Sam Cameron for his encouragement to work on this subject and for his insightful comments on a previous draft. 


\section{Introduction}

When the words "black" and "music" appear in the same sentence, the most obvious guess is that someone is using a politically incorrect term for "Afro-American music" (say, jazz or blues). However, a much more likely subject in Italy would be the situation of the musicians' labour market. Estimates of the Italian musicians' union (Sindacato Italiano Artisti della Musica) ${ }^{1}$ put the percentage of Italian musicians who work entirely or partially on the shadow market at an average of $95 \%$ for the last few years; the remaining $5 \%$ are either employed as classical musicians (about 1.5\%) or have enough bargaining power (because of their success) to earn a living as self-employed pop artists (about 3.5\%). While there are, to the best of my knowledge, no hard data on the subject, it seems reasonable to believe that, as is often the case in Italian labour markets, people tend to be stuck on whatever side they happen to land at the beginning of their career: if they manage to get a regular job early on, they are likely to keep it for the rest of their lives, otherwise they tend to stay in the black market for as long as they are willing to work as musicians. This is at least what casual observation suggests, and also what the union claims.

Now, it is true that the shadow economy is an important feature of the Italian society: Schneider and Este (2002) estimate its size at about one quarter of GDP in the '90, to be compared with an average of $12 \%$ for developed countries as a whole. Still, a labour market for a perfectly legal job that is almost entirely irregular is something worth our attention. In this note, we strive to understand the forces that have led to such a peculiar situation. In order to do so, we build a theoretical model in which we embed the main institutional features of the Italian system - in particular, social security. We identify, within a second-best setting, a natural tendency for the musicians' labour market to split into a regular part and an irregular one, and point out that in Italy prominent institutional features exacerbate, rather than compensate, this tendency. This way, we are able to explain the overwhelming prevalence of the black labour market in the case of musicians, and also to point out the policy reforms needed to reverse this state of affairs. We discuss how the reforms might affect social welfare and whether they are politically feasible. We notice that the most promising policy instrument is a unemployment benefit for full-time musicians; under certain circumstances, raising such a benefit may turn out to be Pareto-improving because it induces more talented individuals to choose a career

\footnotetext{
${ }^{1}$ See the union's website, www.sindacatomusicisti.it, accessed January 2009; the site is in Italian.
} 
as regular, full-time musicians, and the revenue raised from taxing the income of these new musicians might then more than offset the increased revenue requirement. Although the model is geared to interpret the Italian situation, we identify some insights that have general validity for any musicians' labour market. Our analysis applies to other workers in the entertainment industry, e.g. actors.

The paper is structured as follows. In Section 2 we provide the institutional and theoretical background. Section 3 illustrates our modelling strategy. Section 4 includes the analysis and the main results. Section 5 rounds off the paper with a final discussion.

\section{Background}

In our model, individuals are partitioned into two groups, those who do not have talent for becoming musicians, work in an ordinary labour market and purchase music, and those who happen to have such a talent (which we take to be exogenously given - more on this later). The talented agents may decide to become full-time self-employed musicians or to enter the ordinary labour market, work full-time there, and also part-time as musicians. ${ }^{2}$ Notice that, while in principle anybody can handle two jobs, it is definitely easier for musicians and other workers in the entertainment industry, because the working hours of an ordinary job and a musician's job are compatible: people want to be entertained in their free time, that is at night, during the week-end or the summer holidays. Hence, although the arguments that we develop in what follows could be applied to other situations, they make sense especially for the case of entertainment workers. ${ }^{3}$

In principle, both jobs could be regular, but there are obvious incentives to keep one on the shadow market; the first job is enough to gain access to several welfare services, and given the progressivity of the tax system, the extra-income from the second job would be relatively modest. Since the income flow of a musician is bound to be highly erratic relative to that of an ordinary worker, due to such things as the vagaries of musical tastes or the competition from DJ's and others who use pre-recorded music, it generally makes sense to keep the employment

\footnotetext{
${ }^{2}$ We are not interested here in the superstar phenomenon (originally studied by Rosen 1981 and Adler 1985 and then generalised to non-artistic labour markets by Frank and Cook 1995); we consider all musicians to be "normal" ones. Casual observation as well as the data we cited above suggest that this is a safe modelling strategy, as only a tiny percentage of musicians become superstars.

${ }^{3}$ Most of what we say about musicians would be true for other artists, e.g. actors.
} 
as musician in the shadow market. We will later illustrate the conditions under which agents actually prefer to go black, and argue that they are often satisfied in the Italian context. Of course, there are limitations to what a moonlighting musician can do - for example, touring is going to be more difficult, due to the demands of the "day job". We will take this into account in the model by the simple expedient of assuming that there are less days available for working as a musician when one is in the shadow market. Another simplification is that we rule out the possibility of black markets for ordinary jobs.

\section{The institutional features ${ }^{4}$}

As we will argue later, the tendency of musicians to work on the shadow market is, at least potentially, present in any second best economy. In Italy, it is compounded by the peculiar features of the welfare system for the workers in the entertainment industry, especially the fact that pension contributions for any particular year are lost if a musician does not work at least 120 days in that year. Abstracting for a moment from the possibility of fiscal inspections, if a musician is uncertain as to the number of days she will have the opportunity to work, then she will only pay the contributions if she estimates a sufficiently large likelihood that this number is higher than 120; otherwise, she would rather go "black". For example, if a musician works only at week-ends, there are at most 104 days available; obviously, the individual might decide not to moonlight only if tax inspectors constitute a real danger (which is generally not the case in Italy). It is true that a musician is entitled to a (modest) unemployment benefit if she works less then 78 days in one year, but the gap between 78 and 120 is rather large and the incentives to moonlight remain basically the same: working for 104 days, one loses both the benefit and the pension contributions. Also, unlike all other workers in Italy, employees or self-employed, musicians do not have access to a publicly subsidised insurance system, despite the fact that the stage is an obviously dangerous working place. This hardly qualifies as a workers' welfare system; perhaps those who designed it shared the view of the anonymous character in the Dire Straits song "Money for nothing", who wistfully notices of musicians that "...them guys ain't dumb...that ain't working, that's the way you do it, get your money for nothing..."

\footnotetext{
${ }^{4}$ This subsection includes a brief description of the italian welfare system for musicians that is based on the information given on the ENPALS's website, www.enpals.it, accessed January 2009. Also this site is in Italian. ENPALS (Ente Nazionale di Previdenza e Assistenza per $i$ Lavoratori dello Spettacolo) is the agency that manages social security for all workers in the entertainment industry.
} 
It is worth remarking that the rules concerning public pensions in Italy impose that the benefit paid to the retired worker is directly related to the total amount of contributions. The system is of the "pay-as-you-go" variety, but, starting from 1995, the benefits are computed according to a formula that mimics the fully-funded systems; the total amount of contributions, plus the interests paid by the State, ${ }^{5}$ determine the total amount of benefits, and the yearly benefit is given by this total amount divided by the number of years a person is expected to live as a pensioner. This makes the fact that pension contributions for musicians are only valid conditional on a minimum number of worked days extremely peculiar. A year in which a musician works little would add little to the total pension benefits to which he or she is entitled, but still it is unclear why he or she should be made to lose the contributions. Possibly, the idea is to force a person into a career - either you are a full-time musician, and then you are entitled to the social security services, or you should definitely leave the music world, and go for an ordinary job. As it happens, the outcome is that most talented individuals do go for an ordinary job, but moonlight as musicians.

Finally, we notice that, whatever the origin of these peculiar arrangements, there are now strong interests against any change of the status quo. There are obvious positive financial consequences for the institution managing the pension system when a substantial share of the workers pay contributions but do not get benefits. As a matter of fact, in Italy musicians and other workers in the entertainment industry have their social security system managed by a separate agency (ENPALS, see fn. 4), that in these latest years has been using (or trying to use) the extra-revenue from the "lost" contributions to help cover the expenses for the current pensions, computed before the 1995 reform with a very generous formula that did not take the amount of paid contributions into account. It is clearly in the interest of the management of ENPALS to keep the current state of affairs unchanged, as long as they are able to enforce the payment of contributions also from musicians who work less then 120 days per year (and possibly more than 78). The musicians' union's main charge against ENPALS is in fact that the latter redistributes resources away from the currently working musicians towards current pensioners - with the aggravating circumstance that the latter come mostly from the elite of employed classical musicians or successful pop artists. At a more general level, we can also point out that the current pension system for musicians is, unlike the one prevailing for all

\footnotetext{
${ }^{5}$ The interests paid each year cover the inflation rate plus a spread proportional to the rate of growth of national income. For a detailed presentation of the Italian pension system after 1995, see Sartor (2001).
} 
other workers, actuarially unfair, that is it implies an expected benefit which is less than the contributions paid.

\section{Models of artists' labour market}

Apart from the superstar models referred to in fn. 2, which we do not consider for the reasons given there, another dominant paradigm in the modelisation of artists' labour markets is the work-preference approach pioneered by Throsby (1994) - see also Cowen and Tabarrok (2000) and Caserta and Cuccia (2001) for subsequent developments. As is well-known, these models postulate that artists have special utility functions. Unlike other workers, who derive utility only from their net income/consumption, artists gain utility also by working in their artistic occupation. Since their earnings from this occupation are however generally low and somewhat erratic, artists allocate their time partly to utility-generating but poorly paid artistic work, and partly to disutility-generating but better paid non-artistic work. Given the assumed preference structure, this behaviour is of course perfectly rational and indeed risk-minimising.

In the present paper, as mentioned, we assume that artist have a special talent for music. It is understood, although not explicitly modelled, that the special talent is acquired through some form of education and training. To keep the model simple, we treat the talent as exogenous, but the reader should keep in mind that, behind the scenes, there has been a stage of human capital accumulation. Unlike the work-preference model, no intrinsic reward is associated to composing or performing music. However, the two modelling strategies are basically equivalent in their predictions, most notably both plausibly describe artists as having more than one occupation. We have chosen the present version because it is more amenable to the tax/benefit analysis that is crucial to our reasoning.

\section{A model of the musicians' labour market in Italy}

We employ an extremely simple overlapping generations model. Consider a population whose total size (constant over periods) is normalised to unity; a share $\alpha$ of the individuals are untalented, whereas the remaining $1-\alpha$ are endowed with a talent for music. In the $\alpha$-group, individuals are differentiated by an ability parameter, which we normalise as being equal to the fixed per-period income he or she earns on the ordinary labour market; income is continuously distributed on the support $\left(w^{-}, w^{+}\right)$and $f(w)$ is the corresponding distribution function. Also the agents in the $(1-a)$-group are differentiated by the same ability parameter, now equal to 
the fixed income they could earn on the ordinary market, should they decide not to work as full-time musicians; the support is the same, and the distribution function is $g(w)$. The share of agents who combine the ordinary and the musician's job is denoted $\beta$; the share of full-time musicians is instead $\gamma-$ of course, $\beta+\gamma=1-\alpha$. Agents live for 2 periods, working in the first, and spending the second as pensioners; we use in fact a slightly modified version of the usual life-cycle model, often employed for studying intertemporal policy issues. In each period, there are two generations alive, one of workers and the other of pensioners. The economy replicates itself unvaryingly period after period; hence, we will not use a generation index in our notation below.

\section{Ordinary workers}

Non-musicians consume a composite good $c$ in periods 1 and 2 ; for simplicity, we take it that they only consume $m$ in period $2 .{ }^{6}$ The composite good is produced in a perfectly competitive industry, with linear technology and labour as the only (variable) input; the production price is normalised to unity. Music is only produced and consumed as live shows and it is measured in days (one day=one show). The price $\xi$ of a music show is endogenous; at this stage, however, we consider the behaviour of the agents once it has been agreed upon, and later we will illustrate how it is determined (the usual backward solution strategy). Notice that $m$ takes discrete values, and we take it to be outside the choice of the consumer: to rationalise this, we assume that agents cannot control neither the number of shows that are interesting for them (that depends of course on the schedules of the artists) nor the number of the ones they can actually attend among those (unforeseeable circumstances like bad weather or illnesses may force them not to go). As a further simplification, we take $m$ to be the same for all agents. This latter point is in fact inessential and is only meant to save on notation; the crucial assumption is the exogeneity of $m$, not that fact that it is equal for all. The role of the exogeneity assumption is to simplify the derivation of the musicians' income from their activity; by keeping the number of attended shows fixed, we can more easily model the endogenous determination of the price at which the tickets for the shows are sold (and thus of the earnings of the musicians).

The agent's gross income is simply $w$. Disposable income, though, depends on the impact

\footnotetext{
${ }^{6}$ As pensioners have more free-time than working adults, it is not too far-fetched to think of them as the only ones who consume music. At the expense of some additional complexity, we could include also adults in this category.
} 
of policy; we consider two forms of public intervention: redistributive taxation and pensions. At this stage of the analysis, the reason why these policy instruments have come into being is immaterial - they might have been imposed by a benevolent dictator, or generated by a political process. All that matters is that they are in place, and constrain the agents' behaviour. We choose the simplest possible form of second-best redistributive taxation, the linear income tax, made of a constant marginal income tax rate $t>0$ and a uniform lump-sum subsidy $T>0$. The gross tax liability increases at a constant pace with income, while the subsidy is the same for everybody, so that high-income agents pay into the system more than they get out of it; this makes the linear income tax a simple but effective approximation of real-world progressive tax systems. The lump-sum subsidy, in particular plays the role of what in the real-world are tax allowances. Notice that since income is fixed, the marginal tax rate does not distort the time allocation; however, as we shall see, it may distort the occupational choice for musicians. ${ }^{7}$ Also, agents have to pay for their pensions, and we take $\theta$ to be the proportional rate of pension contribution. The first period budget constraint is thus

$$
c_{o w}^{1}+s_{o w}=(1-t-\theta) w+T
$$

where the superscript denotes the period, the subscript denotes the agent type (ow for ordinary worker) and $s$ are savings. Once retired, the agent's disposable income equals his pension benefit plus the returns from his savings. Since national income is constant over time, and there is no inflation, ${ }^{8}$ the pension benefit, computed according to the Italian method described above, is $\theta w$; that is, it equals the contribution paid. The pension system simply shifts consumption from one period to the next. ${ }^{9}$ The second period budget constraint, with $r$ denoting the interest rate, is

$$
c_{o w}^{2}+\xi m=\theta w+(1+r) s_{o w} ;
$$

solving the second-period budget constraint for $s$, and substituting into the first-period constraint, we obtain

$$
c_{o w}^{1}+\frac{\xi m+c_{o w}^{2}}{1+r}=\left(1-t-\theta\left(1-\frac{1}{1+r}\right)\right) w+T
$$

\footnotetext{
${ }^{7}$ On the income tax, its various forms, and its effects, see e.g. Myles (1995).

${ }^{8}$ Actually, this is not far from what has been actually happening in the last few years in Italy, where national income has been almost stagnant, and inflation has been rather modest.

${ }^{9}$ The coefficient $\theta$ is assumed to give the net-of-taxes pension; this way, we simplify the notation by not explicitly considering taxation in period 2 .
} 
Writing

$$
\tau=t+\theta\left(1-\frac{1}{1+r}\right)
$$

for the "effective" tax rate faced by the individuals, we can simplify the notation:

$$
c_{o w}^{1}+\frac{\xi m+c_{o w}^{2}}{1+r}=(1-\tau) w+T .
$$

It is worth noting a feature of the model that plays a somewhat hidden role in shaping the budget constraint. In order to be realistic, one has to assume that the pension system is of the pay-as-you-go variety, that is current contributions are immediately employed to cover the expenditure for current pensions. That being the case, it would not in general be true that any single agent could get as a pension exactly what he had to remit in contributions and that at the same time the budget of the social security agency could break even. In our case, it is however true, because the economy replicates itself period after period without changing.

We postulate an extremely simple utility function for the ordinary workers, in which the consumption of live music shows enters linearly, and the consumption levels of the composite good in the two periods are regarded as perfect complements:

$$
U=\min \left[c_{o w}^{1}, c_{o w}^{2}\right]+\pi m
$$

where $\pi$ is the utility (measured in consumption units) from an additional music show. This modelling strategy is dictated by the opportunity to keep the model as uncluttered as possible in all the aspects that are not central to the analysis. Using this utility function, we can derive immediately the optimal consumption path of the agents, and, using the fact that the marginal utility of a music show is fixed, we can approach the bargaining stage for the determination of the musicians' income in a straightforward way, as we shall see presently. No other property of the model or result of the analysis is in any way dependent on the simplified utility function that we use; in particular, the partition of the labour market between full-time and part-time musicians that we derive later on stems exclusively from the assumption that only some agents have a talent for music, and not at all from the form of the utility function.

We know that maximising (6) subject to (5) requires that $c_{o w}^{1}=c_{o w}^{2}$; letting $c_{o w}$ denote the common consumption level, is then easy to find that

$$
c_{\text {ow }}=\left[(1-\tau) w+T-\frac{\xi}{1+r} m\right] \frac{1+r}{2+r} .
$$

Substituting $c_{\text {ow }}$ back into the utility function, we obtain an expression for the indirect utility, which we express as a function of the policy variables, $U^{*}(t, T, \theta)$. Using the envelope theorem 
we note for future use the following properties:

$$
\frac{\partial U^{*}}{\partial t}=-w \frac{1+r}{2+r}<0 ; \frac{\partial U^{*}}{\partial T}=\frac{1+r}{2+r}>0 .
$$

To further emphasise the limited impact that our choice for the utility function has on the development of the model, we remark here that the signs of the above derivatives are valid for all utility functions - only the specific functional forms follow from our specific utility function. Of course, the results that we derive in Section 4 below only depend on the signs.

\section{Full-time musicians}

Musicians, on the other hand, only enjoy the composite good, so their utility function can be represented as

$$
U=\min \left[c_{i}^{1}, c_{i}^{2}\right]
$$

where $i=f m, p m$ denotes a full-time or a part-time musician. Starting with the former, we take it that the number of days a full-time musician works in the first period is a discrete random variable that can take three values, $d^{a}, d^{a}$ and $d^{c}$, with probability $p^{a}, p^{b}$ and $p^{c}$, respectively; we posit $d^{a}>d^{b}>d^{c}$. The expected value is

$$
\delta=p^{a} d^{a}+p^{b} d^{b}+p^{c} d^{c}
$$

For each worked day, the musician earns $x=n(\xi-\chi)$ units of consumption good, where $n$ is the share of the untalented population that happens to attend the show and $\chi$ is the cost of the show borne by the musician. So, total expected gross income in the first period is $\delta x$. Expected net income depends on how policy interacts with the agent's actions. A musician pays the income tax and the pension contributions, and receives the subsidy, the same as the ordinary worker; moreover, if he works $d^{c}$ days he is entitled to an unemployment benefit $\sigma$ paid by the State. That is, we assume that the state provides a form of social insurance to compensate the fact that the income of musicians is uncertain, unlike that of ordinary workers (this captures an essential feature of the current situation in Italy, as described above). Thus, the budget constraint in period 1 is

$$
c_{f m}^{1}+s_{f m}=(1-t-\theta) \delta x+T+p^{c} \sigma .
$$

As for the pension benefit, we assume that only if the agent works $d^{a}$ days, its contributions are valid towards the computation of the benefit (this again reflects the current institutional 
setting in Italy). Thus, the pension benefit is given by $\theta p^{a} d^{a} x$, and the budget constraint is

$$
c_{f m}^{2}=\theta p^{a} d^{a} x+(1+r) s_{f m} .
$$

The problem of a full-time musician is then to maximise (9) s.t.

$$
c_{f m}^{1}+\frac{c_{f m}^{2}}{1+r}=(1-t-\theta) \delta x+T+p^{c} \sigma+\frac{\theta p^{a} d^{a} x}{1+r} .
$$

The solution is identified by

$$
c_{f m}=\left[(1-t-\theta) \delta x+T+p^{c} \sigma\right] \frac{1+r}{2+r}+\frac{\theta p^{a} d^{a} x}{2+r} .
$$

Deriving the indirect utility function as before, and denoting it as $u^{*}(t, T, \theta, \sigma)$ we obtain the following model properties:

$$
\frac{\partial u^{*}}{\partial t}=-\delta x \frac{1+r}{2+r}<0 ; \frac{\partial u^{*}}{\partial T}=\frac{1+r}{2+r}>0 ; \frac{\partial u^{*}}{\partial \sigma}=\frac{1+r}{2+r} p^{c}>0 .
$$

The same caveat as before applies: the signs are independent of the specific utility function, although the functional forms of course are not.

\section{Part-time musicians}

We assume that moonlighting is always a superior option to keep music as a regular second job (later in this subsection we give the precise condition under which this occurs); given the data we gave on the employment of musicians in Italy, this is clearly an empirically plausible assumption. Thus, part-time musicians' gross incomes are given by $w$ plus what they earn on the black market. We assume that moonlighting involves a cost, in that the agent must hide his activity from the fisc. In the relevant literature, tax dodging is modelled either as avoidance (a costly but riskless activity) or evasion (risky because of tax inspections and consequent fines) - see e.g. Cowell (1990b). We use the avoidance approach, following Slemrod (2001) among others, because it is analytically simpler; in our case, however, we do not interpret avoidance literally as depicting a situation in which there are no chances to be discovered once the cost is incurred, but as a reduced form of the evasion approach. To do so, we think of the cost of avoidance as the "monetary amount that the person would just be prepared to pay in order to be guaranteed that he will get away with evasion" (Cowell, 1990a, p. 232 - see also Balestrino and Galmarini, 2003), thereby converting a problem of choice under uncertainty into an equivalent one under certainty. Finally, notice that the cost of avoidance depends, in principle, also on 
policy: the government decides how much effort to put into the enforcement of the tax code. We will not particularly pursue this line of enquiry in the paper, letting enforcement be fixed at some exogenous level for most of the analysis; however, we refer occasionally to what might happen if enforcement could be controlled.

Thus, we let $d$ be the number of days a part-time musician can work on the black market, and $k(d)$ be an increasing and strictly convex function describing the cost of moonlighting. Then, gross income in the working period is

$$
w+d x-k(d)
$$

Taking into account the policy instruments, the budget constraint is

$$
c_{p m}^{1}+s_{p m}=(1-t-\theta) w+T+d x-k(d) .
$$

Since pension benefits are computed as for ordinary workers, the constraint in the second period is

$$
c_{p m}^{2}=\theta w+(1+r) s_{p m}
$$

Then, the combined budget constraint is

$$
c_{p m}^{1}+\frac{c_{p m}^{2}}{1+r}=(1-\tau) w+T+d x-k(d)
$$

It turns out to be convenient to interpret the part-time musicians' maximisation problem as a two-step process; first, they choose the optimal number of moonlighting days, that is they maximise their total income; given this, they choose their intertemporal consumption allocation. The first step is characterised by the first order condition

$$
x=k^{\prime}
$$

we let $d^{*}=d(x)$ be the optimal number of moonlighting days; given that the cost function $k(d)$ is independent of $w, d^{*}$ does not vary across agents. Maximised lifetime income is thus $(1-\tau) w+T+d^{*} x-k\left(d^{*}\right)$.

At this stage, we can rationalise the assumption that part-time musicians always moonlight rather than having two regular jobs. Suppose that the largest number of worked days as a musician compatible with the working schedule of the ordinary job is $\bar{d}$; then, the net lifetime income from the second job is $(1-\tau) \bar{d} x$. We are assuming that

$$
d^{*} x-k\left(d^{*}\right)>(1-\tau) \bar{d} x .
$$


In the second step, part-time musicians maximise (9) s.t.

$$
c_{p m}^{1}+\frac{c_{p m}^{2}}{1+r}=(1-\tau) w+T+d^{*} x-k\left(d^{*}\right) .
$$

The solution is

$$
c_{p m}=\left[(1-\tau) w+T+d^{*} x-k\left(d^{*}\right)\right] \frac{1+r}{2+r} .
$$

Finally, we again derive the indirect utility in the usual way, and compute

$$
\frac{\partial u^{*}}{\partial t}=-w \frac{1+r}{2+r}<0 ; \frac{\partial u^{*}}{\partial T}=\frac{1+r}{2+r}>0 .
$$

Once again, we remark that the signs of these derivatives are independent of the functional form of the utility function.

\section{Bargaining over the price of a music show}

We have now all the elements for investigating the determination of the price of a music show. Our intent in making such price endogenous was to capture, simply but effectively, the way in which a musician's income is formed in the real world, where it would depend on how well he manages to sell his or her shows. Of course, in the real world there are additional actors besides the consumers and the producers of music, such as the musician's agent and the owner of the venue where the show is performed. In our simplified setup, we suppose that bargaining takes places directly between the consumers and the musicians, dispensing with these intermediaries it would actually be easy to account for their role, but the model would only gain an additional layer of complexity without generating any further insight. We have also built the model so as to make this bargaining stage as simple as possible, in such a way that it generates the same price for all possible consumer-musician interactions (that is, the price does not depend on the consumer's income).

Let us take then a typical situation in which an ordinary agent and a musician bargain over the price of the show. If an agreement is found, the ordinary agent gains $\pi-\xi$, whereas the musician gains $\xi-\chi$; both have a fall-back positions of zero gains and zero losses if the bargain is not struck (i.e. bargaining takes place before costs are incurred). Therefore, a simple Nash solution is found by choosing $\xi$ so as to maximise

$$
N=(\pi-\xi)^{\mu}(\xi-\chi)^{1-\mu}
$$


where $\mu \in(0,1)$ denotes the bargaining power of the buyer (the ordinary agent) and $1-\mu$ the bargaining power of the seller (the musician). The solution is

$$
\xi=\mu \chi+(1-\mu) \pi
$$

that is the price is a weighted average of the cost and of the marginal utility of a show, with the weights given by the bargaining power parameters. For the model to work, we have to assume that $\pi>\chi$, so that $\xi$ necessarily falls between $\pi$ and $\chi$; this way, both buyer and seller have something to gain from reaching an agreement.

Importantly, the price is directly proportional to the marginal utility $\pi$, which we can interpret as the consumer's willingness to pay for the show (it is in fact expressed in units of the numeraire). We will argue that $\pi$ is relatively small, since musical tastes, in Italy like elsewhere, are today biased towards the English-speaking world. ${ }^{10}$ Our contention is that the deep differences existing between the two musical traditions imply that as consumers learn to appreciate English/American music, their willingness to pay for listening to Italian music is reduced. Indeed, Italian music is based on a tradition going back at least to the second half of the XVI century, according to which songs are built along a melodic line with chord-based accompaniment (a melody is a sequence of notes; a chord is obtained instead when three or more notes sound simultaneously). In these compositions, rhythm is relatively unimportant and largely unvarying throughout the piece, whereas much importance is attached to the singer's technical abilities. Over the centuries, the songwriting, playing and singing styles have become uniquely Italian inasmuch as the melodies have to adapt themselves to a country's language. In the XIX century Romantic musicians like Verdi also became nationalistic icons (for more on these issues, see e.g. Griffiths, 2006). Against this deeply rooted and value-laden tradition, influences from the English-speaking world have brought to Italy jazz, blues, rock'n'roll, progressive rock, electro-pop, disco music, rap, hip-hop and a variety of other genres and sub-genres, some more sophisticated, other definitely popular. For most of these genres, rhythm is key in terms of what "makes the song", and even when melody matters, it will be a melody suitable for the Anglo-Saxon language or perhaps left to an instrument as opposed to the vocal part. It is easy to imagine that as the consumers get used to such a foreign musical style, they will not express

\footnotetext{
${ }^{10}$ In the context of our model, Anglo-Saxon music, that can be enjoyed e.g. by purchasing CD's or music DVD's or attending shows from American or English singers/groups when their tours touch Italy or the limitrophe countries, is included into the composite good $c$; we built the model in such a way that the willingness to pay $\pi$ concerns exclusively live shows by Italian musicians.
} 
a particularly large willingness to pay for Italian music: $\pi$ will be relatively low, and so will be $\xi$, and consequently the income that the musicians can earn from their shows. ${ }^{11}$

\section{The labour market equilibrium and the role of policy}

The labour market for ordinary workers presents no particular features. It is instead necessary to determine the partition of musicians into full- and part-timers. From the way we set up the optimisation problem of the two categories of agents, it is clear that a musician will work part-time as long as the disposable income he enjoys exceeds the income he would have working full-time (and viceversa). This follows because the two types of musicians have the same utility function, and therefore their maximised utility will be higher the larger is their total income.

\section{The partition of musicians in first and second best}

In order to appreciate the peculiarity of the Italian institutional setting, we adopt a three-step procedure. First, we establish a double benchmark by showing how the partition criterion would work: i) in a laissez-faire situation, without policy, and ii) in a generic second-best setting in which the pension system is actuarially fair also for musicians. Only then we consider the Italian case.

In laissez-faire, the part-time work as musicians would not be intended as moonlighting, but simply as a second job, and therefore the number of worked days would be the largest compatible with the working schedule of the ordinary job, which we denoted above as $\bar{d}$. A part-time musicians would earn $w+\bar{d} x$ over his lifetime, and a full-time musician would earn $\delta x$; income would be shifted from one period to another through savings. The threshold ability level would then be implicitly identified by

$$
w+\bar{d} x=\delta x
$$

that is

$$
w^{L F}=(\delta-\bar{d}) x
$$

\footnotetext{
${ }^{11}$ One might argue that Italian musicians could learn to play and sing the way American or English musicians do. In fact, this is what superstars often do: we have Neapolitan bluesmen, Tuscanian rappers, and so on. But for the average musician the difficulties of learning a totally different style of playing are often insurmountable (the unusual rhythms of Anglo-Saxon music are for example a big hurdle).
} 
All talented agents with ability strictly greater than $w^{L F}$ would become part-time musicians, and the remaining ones would become full-time musicians. ${ }^{12}$ Plausibly, $\delta>\bar{d}$, that is the number of days a part-time musician can actually work is less than the number of days he expects to work as a full-timer; then, $w^{L F}>0$. This identifies the population shares $\beta^{L F}$ and $\gamma^{L F}$ in laissez-faire:

$$
\beta^{L F}=\int_{w^{L F}}^{w^{+}} g(w) \mathrm{d} w ; \gamma^{L F}=\int_{w^{-}}^{w^{L F}} g(w) \mathrm{d} w .
$$

Clearly, the fraction of full-time musicians (i.e. $\gamma$ ) increases with $w^{L F}$; in this specific case, this implies that the larger is the difference between $\delta$ and $\bar{d}$, the more musicians will choose to become full-timers. This reflects the fact that full-time musicians are those whose earning ability on the ordinary market is lowest; if the possibility to supplement this ordinary income with a second job is limited, then there is a strong incentive to become full-timers.

Let us consider now the partition of musicians in a generic second-best setting. Supposing then that such a pension system works like the one operating in the ordinary labour market, and more precisely that it is actuarially fair, the lifetime income of a full-time musician would simply be

$$
(1-\tau) \delta x+T+p^{c} \sigma
$$

We should find the value of $w$ for which this income equals that earned as part-time musician, that is the value of $w$ that solves

$$
(1-\tau) \delta x+T+p^{c} \sigma=(1-\tau) w+T+d^{*} x-k\left(d^{*}\right),
$$

i.e.

$$
w^{S B}(t, \theta, \sigma)=\delta x+\frac{\sigma p^{c}+k\left(d^{*}\right)-d^{*} x}{1-\tau} .
$$

Of course, $w^{S B}$ determines $\beta^{S B}$ and $\gamma^{S B}$ just as $w^{L F}$ determines $\beta^{L F}$ and $\gamma^{L F}-$ see above. We emphasised that the threshold income depends on the policy instruments; for future use, we compute the following derivatives:

$$
\begin{gathered}
\frac{\partial w^{S B}}{\partial \sigma}=\frac{p^{c}}{(1-\tau)}>0 ; \\
\frac{\partial w^{S B}}{\partial t}=\frac{w^{S B}-\delta x}{(1-\tau)}>0 ; \\
\frac{\partial w^{S B}}{\partial \theta}=\frac{\partial w^{S B}}{\partial t} \cdot \frac{r}{1+r}>0 .
\end{gathered}
$$

\footnotetext{
${ }^{12}$ Those with ability $\widetilde{w}$ are indifferent between the two career options, and we assume that they choose to become full-time musicians.
} 
Hence, marginally increasing the unemployment benefit has an unambiguously positive effect: indeed, a larger unemployment benefit makes the career as full-time musician more appealing, and therefore a larger number of talented agents will choose it. The effects of the income tax rate $t$ and of the pension contribution rate $\theta$ are in principle ambiguous: when either $t$ or $\theta$ changes, it makes both career choices less interesting in absolute terms, but it also changes their relative appeal. For this general second-best setting, it is possible to say which of the two effects prevails: a rise in the tax or in the contribution rate rises the cut-off income level, and therefore makes a career as full-time musicians more appealing.

A question of some interest is to what extent policy distorts the efficient partition of the workers in the two musical careers relative to the efficient laissez-faire solution. This is relevant on at least two accounts. First, there is the general problem of the efficient allocation of resources: if there are too few or too many full-time musicians, then human capital is not being used efficiently, as there are agents who could do better by switching to another job. Second, there is the specific problem of tax avoidance: since in the second-best economy part-time musicians hide a share of their income from the fisc, the partition of musicians matters in terms of revenue - the more full-time musicians there are, the less revenue is lost.

To answer our question, we can simply compare $w^{L F}$ with $w^{S B}-$ the number of full-time musicians is increasing in the threshold income. A few computations yield

$$
w^{L F} \frac{\geq}{<} w^{S B} \text { if }\left[\left(d^{*} x-k\left(d^{*}\right)\right)-(1-\tau) \bar{d} x\right] \frac{\geq}{<} p^{c} \sigma .
$$

Notice that the l.h.s. of the second inequality in (34) is nothing but the "moonlighting condition" (19) that we assumed to be valid in the Italian case. Supposing that the condition holds also for this generic second-best economy, then the term is positive. Hence, the presence of a black market works in the direction of making $w^{L F}$ larger than $w^{S B}-$ in other terms, it favours an inefficiently small number of full-time musicians. There are two ways in which this tendency can be contrasted. First, we might have a relatively large unemployment benefit. Second, it might be that moonlighting is too costly, e.g. because there are effective enforcement procedures that rise $k(d)$ up to the point where the moonlighting condition is no longer satisfied. We can thus state:

Claim 1 In a second-best economy there are inefficiently few full-time musicians if the black market is accessible (i.e. the moonlighting condition holds) and the unemployment benefit is small or indeed absent. 


\section{The partition of musicians in the Italian labour market}

Let us now move to the model that has been devised so as to capture the main institutional features of the Italian situation. The identification of the threshold ability level requires again that we consider the point at which the income from being a full-timer equals the income from being a part-timer:

$$
(1-t-\theta) \delta x+T+p^{c} \sigma+\frac{\theta p^{a} d^{a} x}{1+r}=(1-\tau) w+T+d^{*} x-k\left(d^{*}\right) .
$$

This yields

$$
w^{I T}=\frac{(1-t-\theta) \delta x+p^{c} \sigma+\frac{\theta p^{a} d^{a} x}{1+r}+\left(k\left(d^{*}\right)-d^{*} x\right)}{1-\tau} .
$$

As we know, this means that only agents with ability less than $w^{I T}$ become full-time musicians; $\beta^{I T}$ and $\gamma^{I T}$ are determined as above. Notice that the determination of the value of this threshold (like those of the other thresholds) is also affected by the level of $x$, the income flow accruing to the musician from each show. So far, we have not commented on its role, since in the context of hypothetical first-best or second-best economies, we did not have any way to guess its relative importance. However, in the case of Italy we have argued above that, due to the competition from abroad, the price each consumer pays to attend the show is not likely to be very large; hence, we expect $x$ not to be large either. This clearly tends to discourage musicians from becoming full-time professionals, and identifies a first factor in reducing the absolute number of them in Italy.

A question that naturally comes to mind is whether the distortions encountered in the general second-best case are reinforced in the Italian setting by the presence of the actuarially unfair pension system. Predictably, the answer is positive. To see this, consider first that the conditions of Claim (1) are naturally met in the Italian case; the moonlighting condition is satisfied, and the unemployment benefit is small; thus, we expect that even without the distortion induced by the pension system the group of full-time musicians would be inefficiently small. This latter distortion further complicates things: a comparison between the threshold income for the case of Italy and that for the general second-best setting using (36) and (30), yields, after a few manipulations,

$$
w^{S B}-w^{I T}=\frac{\theta\left(p^{b} d^{b}+p^{c} d^{c}\right) x}{1+r}>0 .
$$

The difference is given, as expected, by the lost benefit - the share of contributions that is not converted into a pension benefit. Then, recalling that a higher threshold income implies more full-time musicians, we may conclude that: 
Claim 2 In the Italian institutional setting, the presence of an actuarially unfair pension system reduces the number of full-time musicians below the level that would prevail if the economy were generically second-best.

In other words, if the workers in the entertainment industry received the same social security treatment as anybody else, the gap between the actual and the efficient size of the group of full-time musicians would be reduced. This conclusion allows us to evaluate critically one of the main demands of the Italian musicians' union - namely that the specificity of the pension system for the workers in the entertainment industry is removed, and that they are treated like ordinary workers (thereby receiving as pensioners the actuarially fair value of their contributions). The arguments put forward by the union are rooted mostly in the horizontal equity principle, stating that agents sharing equal traits should be treated equally - in this case, all workers should receive the same social security treatment. Our analysis provides a somewhat more basic argument: reforming the pension system is needed for efficiency reasons, that is for favouring the proper functioning of the labour market. In practice, it is however difficult to say whether the musicians' union might find the political strength to impose this reform against the short-term interest of the ENPALS management.

Even supposing that the pension system could be changed in the above direction, and the economy could thus be turned into a generic second-best one, efficiency in the musicians' labour market would not be restored (see Claim 1). There is a tendency, inherent to the presence of second-best taxation, to discourage musically talented agents from becoming full-time musicians; this is represented by the l.h.s. of the second inequality in (34). However, there is at least a countervailing policy instrument, the unemployment benefit - appearing on the r.h.s. of the above-mentioned inequality; inasmuch as it provides a form of insurance against the fluctuations of the full-time musicians' incomes, it might in principle offset the negative impact brought about by the income tax. We devote the remainder of this section to an investigation of the role of the unemployment benefit as an efficiency-enhancing instrument.

\section{Restoring efficiency in the second-best economy}

As mentioned above, restoring efficiency matters not only in the general sense that it is desirable to use the available resources efficiently, but also as a way of fighting tax avoidance: by reducing the number of moonlighters, we can increase revenue and the general well-being of the population. 
Now, the discussion leading to Claim 1 seems to suggest a straightforward solution to the question of how to restore efficiency in a generic second-best economy. By setting

$$
\sigma=\left[\left(d^{*} x-k\left(d^{*}\right)\right)-(1-\tau) \bar{d} x\right] / p^{c}
$$

the government would be able to bring the number of agents who work as full-time musicians to its efficient level, as in this case the threshold income $w^{S B}$ equals the efficient laissez-faire threshold $w^{L F}-$ see (34). It remains to be seen, however, how the government can fund the expenditure implied by the unemployment benefit. As public debt is not contemplated in our model, this might be done by raising the tax rate $t$, or reducing the universal subsidy $T$; both options could however be opposed by the ordinary workers (and by the part-time musicians). Apparently, those who work on the ordinary labour market have all to lose and nothing to gain from this sort of reform. This however turns out not to be entirely correct. To give a definitive answer on who gains and who loses, and hence who might oppose and who might favour the reform, we need a more comprehensive analysis that includes the role of the public budget.

To begin with, let us write the overall public budget constraint for each period; the budget of the social security agency does not appear explicitly, as it is always balanced by construction. Assuming no extra-revenue requirement, we have

$$
\begin{aligned}
R(t, T, \sigma) \equiv & t\left(\int_{w^{-}}^{w^{+}} w f(w) \mathrm{d} w+\int_{w^{S B}}^{w^{+}} w g(w) \mathrm{d} w\right)+ \\
& +t \delta x \int_{w^{-}}^{w^{S B}} g(w) \mathrm{d} w-\left(T+p^{c} \sigma \int_{w^{-}}^{w^{S B}} g(w) \mathrm{d} w\right)=0
\end{aligned}
$$

where it is important to keep in mind that $w^{S B}$ is itself a function of the policy variables - see above. This simply says that the revenue from taxing ordinary workers and part-time musicians (first term) plus the revenue from taxing full-time musicians (second term) must equal the total expenditure given by the poll-subsidy and the unemployment benefit (third term). ${ }^{13}$

We will examine two alternative balanced-budget reforms; we raise the unemployment benefit to reduce inefficiency in the labour market, and adjust another policy instrument in such a way that the budget equation remains satisfied. In one case, we adjust the universal subsidy $T$, and in the other case, we adjust the tax rate $t$.

\footnotetext{
${ }^{13}$ This constraint applies to a generic second-best economy; in the Italian case there would be an additional term on the revenue side, given by the musicians' lost contributions - what they have paid but not received back. The analysis that follows is however perfectly valid also for the Italian case, as this term neither affects the computations nor the results.
} 
Consider the $(\sigma, T)$ reform. It must be the case that $(\partial R / \partial \sigma) \mathrm{d} \sigma+(\partial R / \partial T) \mathrm{d} T=0$. A few passages show that this is equivalent to

$$
\left[\left(t\left(\delta x-w^{S B}\right)-p^{c} \sigma\right) g\left(w^{S B}\right) \frac{\partial w^{S B}}{\partial \sigma}-p^{c} \gamma^{S B}\right] \mathrm{d} \sigma=\mathrm{d} T .
$$

The term in brackets represents the complete impact of a marginal change $\mathrm{d} \sigma>0$ on the budget. The direct effect is of course the increase in expenditure on existing unemployed full-time musicians (last term, $-p^{c} \gamma^{S B}<0$ ); there is also an indirect effect coming through the increase in the threshold income and therefore in the number of full-time musicians $-\partial w^{S B} / \partial \sigma>0$ by (32). This will imply a larger expenditure on the unemployment benefit $\left(-p^{c} \sigma<0\right)$ but also a larger revenue due to the enlargement of the tax base, as $\delta x-w^{S B}>0$ by (30). The total effect is therefore not unambiguously negative as one might have expected; if the impact of the enlargement of the tax base is sufficiently strong, it might even be positive, meaning that a the marginal increase in the unemployment benefit determines a budget surplus, to be redistributed uniformly to the whole population through a marginal increase in the poll-subsidy. In this case, the reform would be Pareto-improving, because the increase in $\sigma$ would benefit the full-time musicians, and the increase in $T$ would benefit everybody, as can readily be checked using (8), (14) and (22). Clearly, a Pareto-improving reform would be politically feasible.

Let us now check the $(\sigma, t)$ reform. Proceeding as above, we compute

$$
\begin{gathered}
{\left[\left(t\left(\delta x-w^{S B}\right)-p^{c} \sigma\right) g\left(w^{S B}\right) \frac{\partial w^{S B}}{\partial \sigma}-p^{c} \gamma^{S B}\right] \mathrm{d} \sigma=} \\
=-\left[\int_{w^{-}}^{w^{+}} w f(w) \mathrm{d} w+\int_{w^{S B}}^{w^{+}} w g(w) \mathrm{d} w+\delta x \int_{w^{-}}^{w^{S B}} g(w) \mathrm{d} w\right] \mathrm{d} t
\end{gathered}
$$

where the term within brackets on the r.h.s. represents the change in revenue due to a marginal variation in the tax rate, and it is positive. The same reasoning as in the previous case applies. If the total effect on revenue of increasing the unemployment benefit is positive, then $\mathrm{d} \sigma>0$ requires $\mathrm{d} t<0$; hence, it is possible to actually reduce the income tax rate and keep the budget balanced. Again, the reform is Pareto-improving and politically feasible.

We summarise the analysis so far by stating:

Claim 3 If a marginal increase in the unemployment benefit triggers an increase in revenue, it is possible, under certain circumstances, to devise a Pareto-improving reform that moves the economy closer to the efficient partition of musicians between full- and part-timers.

Clearly, this is a local result, and it needs not survive as a global result. That is to say, the second-best optimal unemployment benefit might not be large enough to fully restore efficiency. 
However, it is at least possible to reduce the inefficiency as long as the larger number of fulltime musicians ensures an increase in revenue. It should also be noticed that, even supposing that one could restore the efficient partition of the labour market, moonlighting would not be eliminated, as the incentives to avoid taxes remain. Thus, the unemployment benefit may act as a substitute for tax enforcement, but only partially. It might however reduce the number of moonlighting musicians to a significant extent, thereby making the usual strategies (more inspections, heavier fines, etc.) less costly and more effective.

\section{Discussion: sketches of Italy}

What can we conclude from the above analysis? Are there lessons to be learned for the musicians' labour market in general, rather than for the specific Italian case? These are the main questions we want to address in these concluding remarks.

As far as Italy is concerned, we identified four plausible culprits for the sad state of affairs in the musician's labour market:

- the high accessibility of the black market: as we saw in the Introduction, a large share of the Italian economy is irregular, and the enforcement procedures are definitely on the lax side, hence we expect the "moonlighting condition" (19) to be satisfied and indeed to exhibit a large positive value;

- the relatively low willingness to pay for Italian music: since musical tastes tend to be biased towards products from the English-speaking world, Italian musicians cannot expect to earn large sums by selling their own shows to Italian consumers, and this makes a career as full-time musician less attractive;

- the low level of the unemployment benefit: in line with the generally "thin" nature of the social security system, little insurance is provided against the large fluctuations of the musicians' income, despite the fact that market-provided alternatives are not available (as it is usually the case for this sort of risk);

- the presence of an actuarially unfair pension system, that forces the vast majority of musicians to pay contributions in excess of the actual value of the benefits to be received in the future and as such is in fact strongly criticised by the musicians' union. 
All four factors contribute, to varying extents, to make a career as professional, full-time musician not particularly appealing and might explain the overwhelmingly irregular nature of the labour market.

In other Western economies, these factors are not necessarily present, or not all of them are. Tax enforcement might be sufficiently strict to keep the size of the black economy under control, musical tastes might not be strongly biased towards foreign products, there might be general programs supporting unemployed individuals, and pensions systems might be not so grossly unfair as in the Italian case. However, at least the first factor is likely to be of some relevance everywhere: second-best taxes do provide an incentive for musicians to moonlight, thanks to the peculiar working hours of their job. It is therefore to be expected that some of the talented agents decide not to take up music as a full-time profession, that is there might be less professional musicians as there should be in an efficient partition of the labour market. If that is the case, we identified a simple policy reform that can remedy this inefficiency: raising the unemployment benefit will encourage more individuals to become musicians full-time. This will in turn make more agents prone to reveal their true tax bases, and the consequent increase in revenue might be large enough to offset the costs of stepping up the unemployment program - might indeed generate a Pareto-improving redistribution via the tax system.

\section{References}

Adler, M., 1985, "Stardom and talent", American Economic Review 75, 208-212.

Balestrino, A. and U. Galmarini, 2003, "Imperfect tax compliance and the optimal provision of public goods", Bulletin of Economic Research 55, 37-52.

Caserta, M. and T. Cuccia, 2001, "The supply of arts labour: towards a dynamic approach", Journal of Cultural Economics 25, 185-201.

Cowell, F., 1990a, "Tax sheltering and the cost of evasion", Oxford Economic Papers 42, 231243.

Cowell, F., 1990b, Cheating the government, MIT Press, Cambridge, MA.

Cowen, T. and A. Tabarrok, 2000, "An economic theory of avant-garde and popular art, or high and low culture", Southern Economic Journal 67, 232-253.

Frank, R. and P. Cook, The Winner-Take-All Society, Free Press, New York, NY.

Griffiths, P., 2006, A Concise History of Western Music, Cambridge University Press, Cambridge, UK. 
Schneider, F. and D. Enste, 2002, The Shadow Economy: An International Survey, Cambridge University Press, Cambridge, UK.

Myles, G., 1995, Public Economics, Cambridge University Press, Cambridge, UK.

Rosen, S., 1981, "The economics of superstars", American Economic Review 71, 845-858.

Sartor, N., 2001, "The long-run effects of the Italian pension reforms", International Tax and Public Finance 8, 83-111.

Slemrod, J., 2001, "A general model of behavioral response to taxation", International Tax and Public Finance 8, 118-128.

Throsby, D., 1994, "A work-preference model of artist behaviour", in A. Peacock and I. Rizzo (eds.), Cultural Economics and Cultural Policies, Kluwer Academic Publishers, Dordrecht, NL. 


\section{CESifo Working Paper Series}

for full list see www.cesifo-group.org/wp

(address: Poschingerstr. 5, 81679 Munich, Germany, office@cesifo.de)

2705 António Afonso and Christophe Rault, Spend-and-tax: A Panel Data Investigation for the EU, July 2009

2706 Bruno S. Frey, Punishment - and beyond, July 2009

2707 Michael Melvin and Mark P. Taylor, The Crisis in the Foreign Exchange Market, July 2009

2708 Firouz Gahvari, Friedman Rule in a Model with Endogenous Growth and Cash-inadvance Constraint, July 2009

2709 Jon H. Fiva and Gisle James Natvik, Do Re-election Probabilities Influence Public Investment?, July 2009

2710 Jarko Fidrmuc and Iikka Korhonen, The Impact of the Global Financial Crisis on Business Cycles in Asian Emerging Economies, July 2009

2711 J. Atsu Amegashie, Incomplete Property Rights and Overinvestment, July 2009

2712 Frank R. Lichtenberg, Response to Baker and Fugh-Berman's Critique of my Paper, "Why has Longevity Increased more in some States than in others?", July 2009

2713 Hans Jarle Kind, Tore Nilssen and Lars Sørgard, Business Models for Media Firms: Does Competition Matter for how they Raise Revenue?, July 2009

2714 Beatrix Brügger, Rafael Lalive and Josef Zweimüller, Does Culture Affect Unemployment? Evidence from the Röstigraben, July 2009

2715 Oliver Falck, Michael Fritsch and Stephan Heblich, Bohemians, Human Capital, and Regional Economic Growth, July 2009

2716 Wladimir Raymond, Pierre Mohnen, Franz Palm and Sybrand Schim van der Loeff, Innovative Sales, R\&D and Total Innovation Expenditures: Panel Evidence on their Dynamics, July 2009

2717 Ben J. Heijdra and Jochen O. Mierau, Annuity Market Imperfection, Retirement and Economic Growth, July 2009

2718 Kai Carstensen, Oliver Hülsewig and Timo Wollmershäuser, Price Dispersion in the Euro Area: The Case of a Symmetric Oil Price Shock, July 2009

2719 Katri Kosonen and Gaëtan Nicodème, The Role of Fiscal Instruments in Environmental Policy, July 2009 
2720 Guglielmo Maria Caporale, Luca Onorante and Paolo Paesani, Inflation and Inflation Uncertainty in the Euro Area, July 2009

2721 Thushyanthan Baskaran and Lars P. Feld, Fiscal Decentralization and Economic Growth in OECD Countries: Is there a Relationship?, July 2009

2722 Nadia Fiorino and Roberto Ricciuti, Interest Groups and Government Spending in Italy, 1876-1913, July 2009

2723 Andreas Wagener, Tax Competition, Relative Performance and Policy Imitation, July 2009

2724 Hans Fehr and Fabian Kindermann, Pension Funding and Individual Accounts in Economies with Life-cyclers and Myopes, July 2009

2725 Ernesto Reuben and Arno Riedl, Enforcement of Contribution Norms in Public Good Games with Heterogeneous Populations, July 2009

2726 Kurt Schmidheiny and Marius Brülhart, On the Equivalence of Location Choice Models: Conditional Logit, Nested Logit and Poisson, July 2009

2727 Bruno S. Frey, A Multiplicity of Approaches to Institutional Analysis. Applications to the Government and the Arts, July 2009

2728 Giovanni Villani, A Strategic R\&D Investment with Flexible Development Time in Real Option Game Analysis, July 2009

2729 Luca Di Corato and Michele Moretto, Investing in Biogas: Timing, Technological Choice and the Value of Flexibility from Inputs Mix, July 2009

2730 Gilad D. Aharonovitz, Nathan Skuza and Faysal Fahs, Can Integrity Replace Institutions? Theory and Evidence, July 2009

2731 Michele Moretto and Sergio Vergalli, Managing Migration through Conflicting Policies: an Option-theory Perspective, July 2009

2732 Volker Nitsch, Fly or Cry: Is Airport Noise Costly?, July 2009

2733 Francesco Cinnirella and Joachim Winter, Size Matters! Body Height and Labor Market Discrimination: A Cross-European Analysis, July 2009

2734 Samuel Bowles and Sandra Polanía Reyes, Economic Incentives and Social Preferences: A Preference-based Lucas Critique of Public Policy, July 2009

2735 Gary Burtless, Lessons of the Financial Crisis for the Design of National Pension Systems, July 2009

2736 Helmuth Cremer, Firouz Gahvari and Pierre Pestieau, Fertility, Human Capital Accumulation, and the Pension System, July 2009 
2737 Hans Jarle Kind and Frank Stähler, Market Shares in Two-Sided Media Industries, July 2009

2738 Pamela Campa, Alessandra Casarico and Paola Profeta, Gender Culture and Gender Gap in Employment, August 2009

2739 Sebastian Gechert, Supplementary Private Health Insurance in Selected Countries: Lessons for EU Governments?, August 2009

2740 Leif Danziger, Endogenous Monopsony and the Perverse Effect of the Minimum Wage in Small Firms, August 2009

2741 Yan Dong and John Whalley, A Third Benefit of Joint Non-OPEC Carbon Taxes: Transferring OPEC Monopoly Rent, August 2009

2742 Valentina Bosetti, Carlo Carraro and Massimo Tavoni, Climate Change Mitigation Strategies in Fast-Growing Countries: The Benefits of Early Action, August 2009

2743 Christina Felfe, The Willingness to Pay for Job Amenities: Evidence from Mothers' Return to Work, August 2009

2744 Jörg Franke, Christian Kanzow, Wolfgang Leininger and Alexandra Väth, Effort Maximization in Asymmetric N-Person Contest Games, August 2009

2745 Bruno S. Frey and Paolo Pamini, Making World Heritage Truly Global: The Culture Certificate Scheme, August 2009

2746 Frank N. Caliendo, Is Social Security behind the Collapse of Personal Saving?, August 2009

2747 Caterina Liesegang and Marco Runkel, Corporate Income Taxation of Multinationals and Fiscal Equalization, August 2009

2748 Chrysovalantou Milliou and Apostolis Pavlou, Upstream Horizontal Mergers and Efficiency Gains, August 2009

2749 Rüdiger Pethig and Christian Wittlich, Interaction of Carbon Reduction and Green Energy Promotion in a Small Fossil-Fuel Importing Economy, August 2009

2750 Kai Carstensen, Oliver Hülsewig and Timo Wollmershäuser, Monetary Policy Transmission and House Prices: European Cross-country Evidence, August 2009

2751 Olaf Posch, Explaining Output Volatility: The Case of Taxation, August 2009

2752 Beatrice Scheubel, Daniel Schunk and Joachim Winter, Don't Raise the Retirement Age! An Experiment on Opposition to Pension Reforms and East-West Differences in Germany, August 2009

2753 Daniel G. Arce, Dan Kovenock and Brian Roberson, Suicide Terrorism and the Weakest Link, August 2009 
2754 Mario Larch and Wolfgang Lechthaler, Comparative Advantage and Skill-Specific Unemployment, August 2009

2755 Horst Raff and Nicolas Schmitt, Buyer Power in International Markets, August 2009

2756 Seppo Kari, Hanna Karikallio and Jukka Pirttilä, The Impact of Dividend Taxation on Dividends and Investment: New Evidence Based on a Natural Experiment, August 2009

2757 Mirco Tonin and Michael Vlassopoulos, Disentangling the Sources of Pro-social Behavior in the Workplace: A Field Experiment, August 2009

2758 Nicole Grunewald and Inmaculada Martínez-Zarzoso, Driving Factors of Carbon Dioxide Emissions and the Impact from Kyoto Protocol, August 2009

2759 Yu-Fu Chen and Michael Funke, Booms, Recessions and Financial Turmoil: A Fresh Look at Investment Decisions under Cyclical Uncertainty, August 2009

2760 Jan-Egbert Sturm and Jakob de Haan, Does Central Bank Communication really Lead to better Forecasts of Policy Decisions? New Evidence Based on a Taylor Rule Model for the ECB, August 2009

2761 Larry Karp, Sacrifice, Discounting and Climate Policy: Five Questions, August 2009

2762 Marianna Belloc and Samuel Bowles, International Trade, Factor Mobility and the Persistence of Cultural-Institutional Diversity, August 2009

2763 Charles Noussair and Fangfang Tan, Voting on Punishment Systems within a Heterogeneous Group, August 2009

2764 Birgit Bednar-Friedl and Karl Farmer, Internationally Coordinated Emission Permit Policies: An Option for Withdrawers from the Kyoto Protocol?, August 2009

2765 Pierre M. Picard and David E. Wildasin, Labor Market Pooling, Outsourcing and Labor Contracts, August 2009

2766 Stefan Voigt and Lorenz Blume, The Economic Effects of Federalism and Decentralization - A Cross-Country Assessment, August 2009

2767 David S. Jacks, Christopher M. Meissner and Dennis Novy, Trade Booms, Trade Busts, and Trade Costs, August 2009

2768 Mario Jametti and Thomas von Ungern-Sternberg, Hurricane Insurance in Florida, August 2009

2769 Alessandro Balestrino, Kind of Black: The Musicians' Labour Market in Italy, August 2009 